\title{
Advokasi Kebijakan dalam Kerjasama Smart City Bandung dan Seoul lewat Kemitraan Sister City tahun 2016-2019
}

\author{
Fahrisya Tiko Septiarika ${ }^{*}$, Enny Suryanjari ${ }^{2}$ \\ 1,2Department of International Relations, Institute of Social and Political Science, DKI Jakarta, 12610, \\ Indonesia \\ *Corresponding Author Email: fahrisyatiko3@gmail.com
}

\begin{abstract}
Liberalism welcomes the most possible way for non-state actors (national government) to be engaged in foreign affairs. Duchacek and Soldatos stresses this thesis in their respective articles about the strong role of federal state engaged in foreign affairs. This research is part of the implementation of smart city cooperation through sister city partnership between Bandung - Seoul municipality where Bandung City government is viewed as subnational actor having the opportunity to implement paradiplomacy practices as a form of activity that is related to foreign policy. Research focusses on policy advocacy during the cooperation. Policy transfer and policy diffusion are methods for understanding cross-border policy advocacy processes. This approach comes from a number of multidisciplinary measures such as comparative politics, Latin American regional politics and international relations. In addition, this approach has not been widely used to explain the efforts of sub-national governments in carrying out cooperation between local governments. This study uses the literature study method to obtain all secondary data consisting of news, reports, other important documents that are processed qualitatively to produce explanatory explanations. This research comes to the conclusion of the realization of paradiplomacy during the cooperation and policy collaboration between two municipalities help to realize efficient and innovative governance (smart city). That, Smart City cooperation is manifested in the Sister City partnership in building Smart LBEG: Smart Living, Smart Branding, Smart Environment and Smart Government.
\end{abstract}

Keywords: policy advocacy, policy diffusion, policy transfer, smart city, sister city, partnership

\begin{abstract}
ABSTRAK
Liberalisme menyambut baik cara yang paling memungkinkan bagi aktor non-negara (pemerintah nasional) untuk terlibat dalam urusan luar negeri. Duchacek dan Soldatos menekankan tesis ini dalam artikelnya masing-masing tentang peran kuat negara federal yang terlibat dalam urusan luar negeri. Penelitian ini merupakan bagian dari implementasi kerjasama smart city melalui kemitraan sister city antara kota Bandung - Seoul dimana Pemerintah Kota Bandung dipandang sebagai aktor daerah yang memiliki peluang untuk melaksanakan praktek paradiplomasi sebagai salah satu bentuk kegiatan yang berkaitan dengan politik luar negeri. Fokus penelitian pada advokasi kebijakan selama kerjasama tahun 2016-2019. Penelitian ini menggunakan metode studi pustaka untuk memperoleh semua data sekunder yang terdiri dari berita, laporan, dokumen penting lainnya yang diolah secara kualitatif untuk menghasilkan penjelasan penjelasan. Penelitian ini sampai pada kesimpulan realisasi paradiplomasi selama kerjasama dan kolaborasi kebijakan antara dua kota membantu mewujudkan pemerintahan yang efisien dan inovatif (Smart City). Kerja sama Smart City diwujudkan dalam kemitraan Sister City dalam membangun Smart LBEG: Smart Living, Smart Branding, Smart Environment dan Smart Government.
\end{abstract}

Kata Kunci: advokasi kebijakan, difusi kebijakan, kemitraan, transfer kebijakan, smart city, sister city

* Copyright (c) 2020 Fahrisya Tiko Septiarika dan Enny Suryanjari

This work is licensed under a Creative Commons Attribution-ShareAlike 4.0 International License.

Diterima: 24 Agustus 2020; Direvisi: 21 September 2020; Disetujui: 29 September 2020 
Khazanah Sosial, Vol. 2 No. 3: 141-154

Advokasi Kebijakan dalam Kerjasama Smart City Bandung dan Seoul lewat Kemitraan Sister City tahun 2016-2019

Fahrisya Tiko Septiarika, Enny Suryanjari

\section{PENDAHULUAN}

Transformasi hubungan internasional telah bergeser dari isu yang bersifat high politics seperti isu keamanan, konflik dan peperangan yang cenderung mengedepankan hard power menuju isu-isu kerjasama (Morgan, 1973). Arus globalisasi mengalami peningkatan yang dapat dilihat dari interaksi dan kerjasama antar negara. Seluruh aspek dari negara diharapkan terus bergerak maju untuk menghadapi era globalisasi serta meningkatkan segmentasi yang cepat di berbagai bidang. Ini yang mendorong negara untuk mengoptimalkan potensi dan sumber daya dimiliki. Dalam sudut pandang liberalisme klasik Kantian, praktiknya kerjasama menjadi tool paling efektif guna mengkatalisasi kooperasi antarnegara. Sedangkan diplomasi menjadi kendaraan strategis untuk merealisasikannya (Jönsson \& Hall, 2005).

Pemerintah telah menyadari diplomasi tak hanya bertumpu pada negara, melainkan aktor-aktor hubungan internasional lainnya seperti Pemerintah Daerah (Neumann \&Wæver, 1997). Kissinger (1955) bahkan menyebut kondisi dalam negeri turut mempengaruhi pelaksanaan politik luar negeri setiap negara. Selain itu, sebutan subnational government yang merujuk pada pemerintah daerah (local government atau municipal) juga muncul dalam Soldatos sebagai penggagas utama paradiplomacy. Demi konsistensi, tulisan ini menggunakan literasi subnational government yang perannya menonjol dalam praktik kerjasama Sister City (Liu \& Song, 2020).

Peran aktif pemerintah daerah sebagai subnational government lebih jauh diterangkan dalam kebijakan otonomi daerah dalam Undang Undang Nomor 32 tahun 2004 tentang Otonomi Daerah yang diperbarui dalam ketentuan Undang Undang Nomor 23 tahun 2014 tentang Pemerintahan Daerah, pada pasal 367 dan pasal 7. Undang undang tersebut mengakui kebutuhan pemerintah daerah demi menjamin pembangunan yang menyejahterakan masyarakat maka subnational government diijinkan untuk menjalin kerjasama dengan entitas luar negeri. Sementara kementerian luar negeri sebagai koordinator penyelenggaraan hubungan luar negeri dan pelaksanaan politik luar negeri hal ini dijelaskan dalam Undang Undang Nomor 23 tahun 2014 tentang Pemerintah Daerah tahun 2014. Kehadiran Undang Undang tersebut memperkuat peran dan wewenang subnational government. Pemerintah daerah diakui sebagai perannya sebagai pelaku hubungan luar negeri (Pujayanti, 2018).

Dengan kewenangan yang dimilikinya, pemerintah kota juga dapat meluaskan akses kerjasama dengan lembaga dan/atau pemerintah daerah di luar negeri. Salah satu inisiasi kerjasama yang banyak dilakukan di berbagai subnational government lain yakni Sister City. Berdasarkan data yang diperoleh dari Sister City International, suatu organisasi internasional non-profit bidang kerjasama kota kembar yang dibentuk oleh Dwight Eisenhower 63 tahun yang lalu, setidaknya terdapat lebih dari seratus negara menjalin kerjasama Sister City satu sama lain (Sister City, 2019).

Kerjasama ini mengusung konsep menggandeng dua kota yang berbeda lokasi dan administrasi politik. Apa yang disebut oleh Duchacek dengan Global Paradiplomacy yang bertujuan menjalin hubungan budaya, ekonomi, dan kontak sosial antar penduduk secara berkelanjutan (Duchacek, 1986; Duchacek \& Duchacek, 2019), Kerjasama Sister City pada umumnya memiliki persamaan (similarities) keadaan demografi dan masalah-masalah yang dihadapi (Kartini, 2014). Dalam konsep Sister City, ini yang disebut dengan prinsip similarities (Ogawa, 2012). Similiarities ini menjadi prinsip penting yang mesti ada dalam menjalin kerjasama sister city (Sister City, 2019).

Konsep kerjasama dua kota ini juga pernah diteliti dalam tulisan "Diplomasi Kota dalam Mewujudkan Zhongguo Meng: Hubungan China Indonesia" yang ditinjau melalui kerja sama Kota Kembar antara Surabaya-Xiamen dan Semarang-Beihai (Bramastya \& Septiarika, 2020). Policy transfer tidak dibahas sama sekali sebagai salah satu unit analisis penelitian. Sehingga, hal ini dapat menjadi salah 
Khazanah Sosial, Vol. 2 No. 3: 141-154

Advokasi Kebijakan dalam Kerjasama Smart City Bandung dan Seoul lewat Kemitraan Sister City tahun 2016-2019

Fahrisya Tiko Septiarika, Enny Suryanjari

argumentasi upaya signifikan Pemerintah Kota Bandung untuk mengimplementasikan kerja sama smart city dalam bentuk kemitraan Sister City.

Pendekatan transfer dan difusi ini baru-baru ini menjadi sangat populer di negara-negara Amerika Latin yang diperkenalkan secara mendalam oleh Mattioli dan Rodrigues (2017). Pendekatan ini berasal dari sejumlah langkah multidisiplin seperti politik komparatif, politik regional Amerika Latin dan hubungan internasional. Pendekatan ini menurut Marsh \& Sharman (Marsh \& Sharman, 2009) sifatnya dapat sebagai pelengkap, sekaligus bermanfaat untuk membangun pola serta menemukan hubungan dialektis antara kebijakan yang diadopsi dan implementasi kebijakan di pemerintah daerah negara tujuan. Dolowitz \& Marsh (2000) menambahkan bahwa pola yang dimaksud dapat berupa adanya tingkat pengetahuan tentang kebijakan, perumusan administrasi, institusi yang terlibat, serta ide penyusunan agenda secara politis yang diperlukan baik yang telah berjalan maupun yang akan dijalankan dalam perumusan kebijakan. Difusi dan transfer kebijakan bermanfaat juga untuk mengetahui kompleksitas dan interpretasi kebijakan dari negara origin ke negara host (Stone, 2012).

Penelitian tentang kerjasama Smart City Kota Bandung telah cukup banyak dilakukan seperti (Adibowo \& Putri, 2016; Hasibuan \& Sulaiman, 2019; Hidayat, 2016; Mursalim, 2017; Rahmadanita et al., 2018). Sejumlah penelitiann ini memiliki kemiripan yang dalam unit eksplanasi, selain memiliki unit analisis yang sama. Hasil penelitian Hidaya misalnya sampai pada kesimpulan bahwa smart city dianggap sebagai alternatif solusi untuk mengatasi persoalan dengan menggunakan unit analisis yakni Empat pilar pembangunan smart city meliputi; Pilar pertama adalah people (pengguna) temasuk karakter dan akhlak, ketaatan terhadap kebijakan (compliance), Pilar kedua adalah mekanisme dan standar pelayanan, termasuk pola hubungan antar stakeholder, mekanisme integrasi layanan publik dan data. Pilar ketiga adalah infrastructure ICT, untuk mengintegrasikan pelayanan dan data (informasi) untuk men-drive semua akses online, media automatisasi seperti infrastrukur jaringan, broadband, data center/cloud, data sharing platform/big data, aplikasi, cctv, dan sebagainya. Pilar keempat adalah struktur kelembagaan smart city untuk melakukan analisator, integrator, evaluator, serta menyelaraskan IT Governance dengan bisnis proses (Hidayat, 2016). Di dalamnya belum menyebutkan bagaimana kebijakan dari kota mitra diadopsi (ditransfer) ke Kota Bandung. Musalim juga berpendapat serupa. Ia menilai .Smart city adalah konsep kota cerdas yang dirancang guna membantu berbagai kegiatan masyarakat serta memberikan kemudahan mengakses informasi kepada masyarakat. Konsep ini menekankan pada tiga konsep, pertama, sebuah konsep yang diterapkan oleh sistem pemerintahan daerah dalam mengelola masyarakat perkotaan, kedua mensyaratkan pengelolaan daerah terhadap segala sumber daya dengan efektif dan efisien dan ketiga smart city diharapkan mampu menjalankan fungsi penyedia informasi secara tepat kepada masyarakat dan mampu mengantisipasi kejadian yang tak terduga.Fokus penelitian ini berada di Kota Bandung yang mana kota Bandung telah memenangkan ajang Smart City Award 2015 yang diadakan oleh majalah Asia's Tech Ecosystem. Mengingat bahwa konsep Smart City ini masih terus berkembang dalam proses pembangunan dan pengelolaan kota di Kota Bandung maka perlu dilakukan penelitian. Penelitian ini menggunakan analisis deskriptif dengan melakukan wawancara dan studi literatur yang mana hasilnya dapat diketahui bahwa sosialisasi mengenai Smart City yang belum merata, infrastruktur yang belum memadai, kurangnya pemahaman aparatur mengenai Smart Citydan Sistem Operasional Prosedur hanya mengacu pada Roadmap Walikota Bandung (Mursalim, 2017) sedangkan Adiwibowo menyoroti praktik paradiplomasi dalam kerjasama Smart City Kota Bandung (Adibowo \& Putri, 2016). Sedangkan Rahmadanita menulis hasil penelitian yang menilai kerjasama lebih menekankan pada aspek kontekstual kebijakan saja daripada pada aspek implentasi kebijakan (Rahmadanita et al., 2018). 
Khazanah Sosial, Vol. 2 No. 3: 141-154

Advokasi Kebijakan dalam Kerjasama Smart City Bandung dan Seoul lewat Kemitraan Sister City tahun 2016-2019

Fahrisya Tiko Septiarika, Enny Suryanjari

Selain itu, pendekatan ini belum banyak digunakan untuk menjelaskan upaya pemerintah daerah dalam melakukan kerjasama antar pemerintah daerah. Kerja sama antara dua kota telah menghasilkan pembangunan ekonomi perkotaan, tata kota, transportasi kota, e-government. Transfer kebijakan dan difusi kebijakan merupakan konsep penting dalam proses implementasi kerjasama yang melibatkan proses advokasi kebijakan. Proses transfer kebijakan ini terjadi pada institusi yang ditunjuk oleh Pemerintah Korea Selatan yang dikoordinasikan di bawah Kementerian Ekonomi dan Investasi Korea Selatan, program ini disebut Knowledge Sharing Program (KSP).

Kerjasama Sister City telah lama dijalankan di beberapa negara dengan sistem pemerintahan federal - negara bagian. Sistem federal ini memberi keleluasaan kepada subnational government dalam menjalankan aktivitas hubungan luar negeri (foreign relations) (Duchacek \& Duchacek, 2019). Seiring dengan perkembangannya, Kota Bandung tercatat paling banyak menjalin kerjasama Sister City. Kota Bandung melakukan kerjasama Sister City dengan dua puluh lima kota di luar negeri, namun berdasarkan data Staff Ahli Bagian Kerjasama Pemerintah Kota Bandung kerjasama yang masih aktif hanya berjumlah empat belas kota di luar negeri (Aju, 2020; Mugia, 2020).

\section{METODE PENELITIAN}

Bagian tulisan ini dimulai dengan intisari pendekatan liberalisme yang tidak membatasi adanya aktor lain di luar aktor negara sebagai unitary actor (aktor tunggal) dalam hubungan internasional. Perdamaian dunia menurut liberalisme dapat diwujudkan dengan lebih mengedepankan kerjasama daripada konflik dan membuka ruang seluas-luasnya bagi aktor lain untuk juga terlibat dalam urusan luar negeri tidak hanya urusan domestik. Bagian tulisan ini mengajak untuk melihat Pemerintah Kota Bandung sebagai entitas subnational government yang diberi wewenang untuk melakukan urusan luar negeri seperti menjalin kerjasama. Konsep menjalankan wewenang untuk dapat melaksanakan fungsi urusan luar neeri yang diijinkan ini disebut dengan parallel diplomacy atau akrab dikenal dengan paradiplomasi (Duchacek, 1986; Soldatos, 1990). Pemerintah Kota Bandung menerapkan paradiplomacy untuk dapat membangun kerjasama smart city dalam kemitraan Sister City.

Dalam penelitian ini, peneliti melandaskan fokus penelitian pada misi yang akan dilaksanakan dalam kerjasama Pemerintah Kota Bandung dan Pemerintah Kota Seoul, yaitu advokasi kebijakan yang terjadi dalam proses pembangunan ekonomi perkotaan, perencanaan perkotaan, transportasi perkotaan, e-government. Manifestasi kerjasama ini mengambil wujud dalam dimensi kebijakan sebagai hasil transfer kebijakan atau policy transfer dan policy diffusion menurut Mattioli dan Rodrigues (2017).

Policy transfer dan policy diffusion merupakan konsep penting dalam proses implementasi kerjasama yang melibatkan proses advokasi kebijakan. Policy transfer dan policy diffusion merupakan pendekatan yang saat ini tengah populer untuk mengetahui proses konvergensi kebijakan dari negara origin ke negara host (Dolowitz \& Marsh, 2000; Marsh \& Sharman, 2009; Rodrigues \& Mattioli, 2017; Stone, 2012). Proses transfer kebijakan ini terjadi pada institusi yang ditunjuk oleh Pemerintah Korea Selatan yang dikoordinasikan di bawah Kementerian Perekonomian dan Investasi Korea Selatan, program ini dinamai dengan Knowledge Sharing Program (KSP). Penelitian ini menggunakan metode studi literatur untuk mendapatkan seluruh data sekunder yang terdiri atas berita, laporan, dokumen penting lainnya yang diolah secara kualitatif sehingga menghasilkan penjelasan yang eksplanatoris.

Policy transfer dan policy diffusion merupakan metode untuk memahami proses advokasi kebijakan lintas negara. Pendekatan ini belakangan cukup populer di negara-negara amerika latin. Pendekatan ini berasal dari sejumlah multidisipliner seperti perbandingan politik, politik kawasan Amerika Latin dan hubungan internasional. Selain itu pendekatan ini belum banyak digunakan untuk 
Khazanah Sosial, Vol. 2 No. 3: 141-154

Advokasi Kebijakan dalam Kerjasama Smart City Bandung dan Seoul lewat Kemitraan Sister City tahun 2016-2019

Fahrisya Tiko Septiarika, Enny Suryanjari

dapat menjelaskan upaya pemerintah subnational dalam menjalankan kerjasama antara local government (Rodrigues \& Mattioli, 2017). Pendekatan ini meneliti bagaimana kebijakan publik disalurkan atau terdifusi dan mekanisme dalam prosesnya.

Marsh \& Sharman (2009) ini berpendapat bahwa literatur tentang transfer kebijakan dan difusi kebijakan bersifat saling melengkapi, tetapi perlu lebih fokus pada lima isu utama yang menarik wawasan dari kedua literatur. Pertama, pekerjaan di setiap area dapat menghasilkan keuntungan dari fokus yang lebih besar pada interaksi yang berubah antara berbagai mekanisme yang terlibat dalam difusi / transfer. Kedua, adanya upaya mengistimewakan struktur, sedangkan literatur seputar transfer kebijakan cenderung mengistimewakan agensi, namun diperlukan suatu pendekatan yang mengakui hubungan dialektis antara keduanya. Ketiga, literatur difusi kebijakan berkonsentrasi pada penemuan pola, sedangkan literatur transfer kebijakan meneliti penelusuran proses, tetapi penjelasan lengkap tentang transfer / difusi perlu melakukan keduanya. Keempat, kedua literatur difusi dan transfer kebijakan mengalami pemilihan kasus linier dengan, khususnya, terlalu sedikit perhatian yang diberikan kepada negara-negara berkembang. Terakhir, meskipun kedua literatur perlu tertarik pada apakah difusi / transfer mungkin berhasil / tidak berhasil, keduanya tidak memuat kriteria yang mungkin digunakan untuk menetapkan keberhasilan dan kegagalan kebijakan.

Secara keseluruhan upaya yang dilakukan pemerintah dalam mewujudkan kerjasama Smart City dalam kemitraan Sister City, menggunakan konseptualisasi milik Dolowitz \& Marsh (2000) bisa dikenali apakah terjadi melalui proses copying, emulation, dan combination. Copying adalah proses policy diffusion yang mana subnational government meniru seutuhnya tanpa melakukan perubahan maupun modifikasi pada kebijakan subnational government lain yang menjadi mitranya. Emulation adalah proses meniru kebijakan pada tataran ide saja yang dicanangkan oleh subnational government lain dengan melakukan sedikit perubahan dan modifikasi yang diperlukan. Combination adalah proses policy diffusion yang meniru kebijakan yang dilaksanakan oleh subnational government lain tetapi menghasilkan output yang berbeda daripada output awal yang diinginkan (Dolowitz \& Marsh, 2000).

\section{HASIL DAN PEMBAHASAN}

\section{Policy Transfer}

Marsh \& Sharman (2009) menyatakan bahwa policy transfer dan policy diffusion menjadi bagian yang sama dalam prosesnya. Terdapat tiga proses yang terjadi dalam policy transfer yakni: learning, competition dan coercion. Policy transfer learning adalah proses ketika kebijakan dari suatu pemerintahan subnasional diijinkan digunakan secara sukarela untuk dijadikan pedoman atau panduan kebijakan pada pemerintahan subnasional lainnya. Dengan policy transfer learning ini maka ada proses advokasi kebijakan terjadi secara dan atas kemauan bersama atau memiliki mutual will.

Policy transfer competition, menempatkan pemerintah Kota Bandung yang mendorong secara mandiri belajar kebijakan dan lebih proaktif dalam mendapatkan advokasi kebijakan dari pemerintah Seoul. Motivasi ini sebagian besar berasal dari keinginan agar dapat mendekati keunggulan Kota Seoul dan menjadikan Kota Bandung lebih baik daripada sebelumnya.

Policy transfer coercion, menempatkan Pemerintah subnasional - pemerintah Kota Bandung untuk mendapatkan advokasi kebijakan dari Kota Seoul didasarkan atas tuntutan sebagai bagian dari suatu organisasi internasional atau anggota dari organisasi internasional. Pemerintah Kota Bandung telah menjadi anggota dari organisasi non-profit Sister City International (SCI). 
Khazanah Sosial, Vol. 2 No. 3: 141-154

Advokasi Kebijakan dalam Kerjasama Smart City Bandung dan Seoul lewat Kemitraan Sister City tahun 2016-2019

Fahrisya Tiko Septiarika, Enny Suryanjari

Melalui bagian tulisan ini, bagian tulisan ini akan membedah bagaimana upaya pemerintah Kota Bandung mengimplementasikan kerjasama smart city dalam kemitraan sister city lewat policy transfer. Ilustrasi tentang policy transfer yang ditemukan dalam sumber sekunder dijabarkan dalam bagian tulisan di bawah ini ("Support for the Establishment of Bus System Reform Strategy in Bandung," 2018). The Seoul Institute, Intelligent Transport Society of Korea, Dongil Eng. Consultants ditunjuk untuk memaparkan kebijakan. Kebijakan ini dipaparkan dalam beberapa fase yakni : Launching Seminar and High-level Meeting (16-19 Oktober 2017 di Bandung), tahap kedua proses Policy Seminar and in-depth Study (tidak ada informasi waktu dan venue kegiatan), tahap ketiga proses Interim Reporting Workshop and Practitioners' Workshop (25-31 Maret 2018), dan fase keempat adalah fase terakhir berisi Senior Policy Dialogue and Final Reporting Workshop. Advokasi kebijakan ini menjadi satu-satunya informasi lengkap yang dapat diperoleh dan berguna untuk memberi gambaran tahapan proses advokasi kebijakan.

Pemerintah Kota Bandung, lewat Departemen Transportasi Kota Bandung meminta advokasi kebijakan dalam forum yang diselenggarakan oleh KSP (Knowledge Sharing Program) di bawah Koordinasi Kementerian Ekonomi dan Keuangan (Ministry of Economy and Finance Korea) Pemerintah Korea Selatan. Advokasi kebijakan ini berjalan kurang lebih selama setahun sejak 2017-2018 dapat dilihat pada gambar 1.

\section{Gambar 1. Proses Policy Transfer dalam Knowledge Sharing Program}

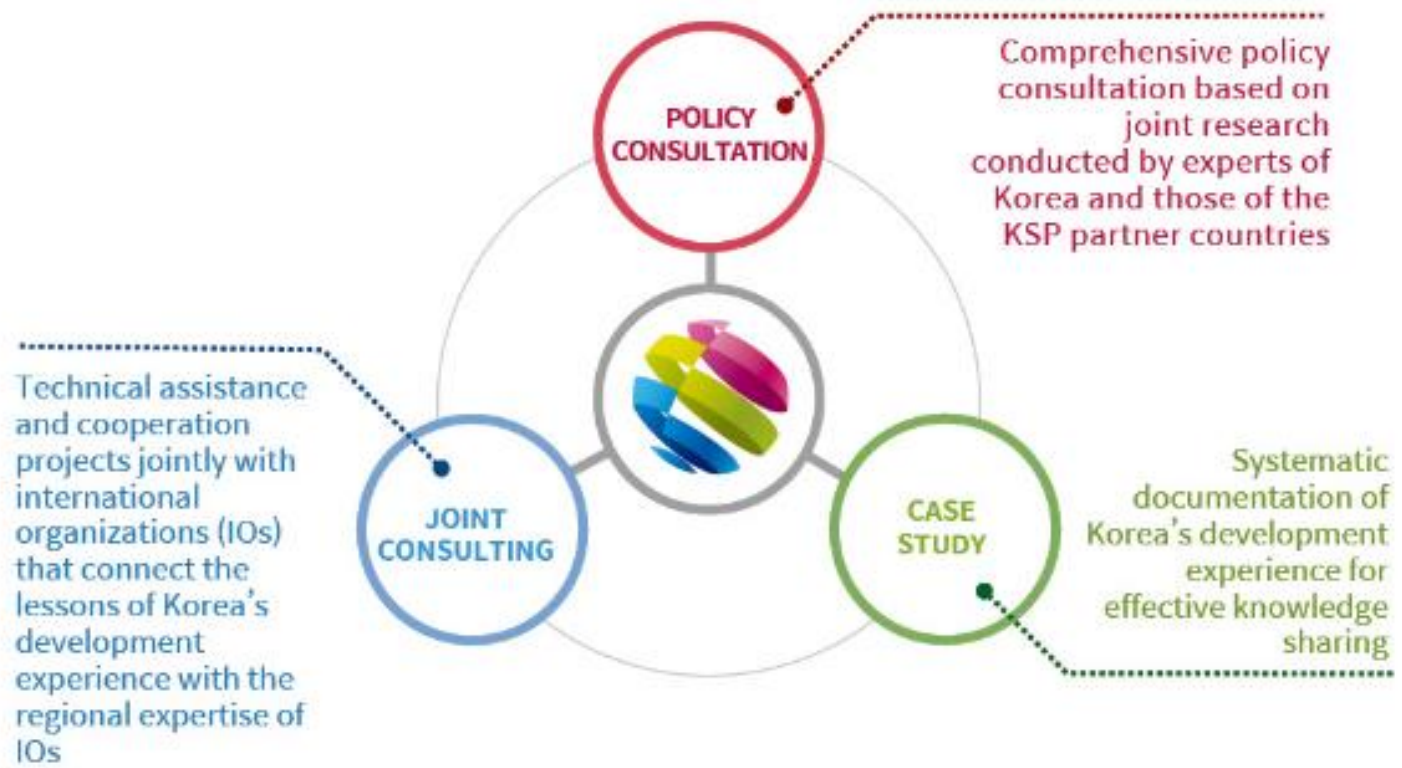

Fase advokasi kebijakan dalam KSP dibagi menjadi tiga. KSP memfasilitasi adanya konsultasi kebijakan, mengangkat studi kasus, dan memfasilitasi dialog bersama dengan mitra. Dalam fase konsultasi kebijakan, KSP mewadahi forum yang secara komprehensif memfasilitasi konsultasi berdasarkan pada riset bersama yang diselenggarakan oleh tenaga ahli terpilih dari Korea Selatan dengan negara mitra KSP. Hal ini bisa dikenali adanya komunikasi antara konsultan yang ditunjuk oleh pemerintah Kota Bandung yakni LAPI ITB. LAPI ITB adalah badan usaha milik Institut Teknologi Bandung (ITB), didirikan untuk menunjang kegiatan akademik ITB melalui kegiatan usaha di bidang konsultansi, pelatihan dan 
Khazanah Sosial, Vol. 2 No. 3: 141-154

Advokasi Kebijakan dalam Kerjasama Smart City Bandung dan Seoul lewat Kemitraan Sister City tahun 2016-2019

Fahrisya Tiko Septiarika, Enny Suryanjari

pengembangan teknologi tepat guna. Dalam menjalankan tugasnya, PT. LAPI ITB didukung oleh ITB (Tentang LAPI ITB, 2020).

Proses advokasi kebijakan KSP juga mengangkat studi kasus yang berisi dokumentasi ilmiah dari pengalaman kemajuan dan perkembangan Korea Selatan secara efektif dan efisien. Studi kasus yang diangkat salah satunya adalah "Support for the Establishment of Bus System Reform Strategy in Bandung 2017/2018'.

Fase ketiga disebut dengan konsultasi bersama atau "joint consulting" yang berisi bantuan teknis terhadap proyek kerjasama bersama dengan berbagai organisasi internasional yang menghubungkan praktik dan pengalaman Korea Selatan dengan tenaga ahli dari berbagai organisasi internasional.

Secara umum, proses advokasi kebijakan lewat KSP yang dapat dikenali dalam berbagai kerjasama Kota Bandung dan Seoul melalui tahapan sebagai berikut:

1. Pertemuan awal (Preliminary Meeting) dengan venue di negara mitra

2. $\quad$ Launching Seminar \& High-Level Meeting dengan venue di negara mitra

3. Seminar Kebijakan dan Studi Mendalam dengan venue di negara mitra

4. $\quad$ Laporan antara dan Workshop Praktisi Kebijakan dengan venue di Korea Selatan

5. Dialog Kebijakan dan Workshop Laporan Akhir dengan venue di negara mitra

6. Konferensi Diseminasi dengan venue di Korea Selatan

Kerjasama Smart City Kota Bandung dan Kota Seoul melalui serangkaian proses di atas. Pemerintah Kota Bandung melalui keanggotaannya dalam SCI (Sister City International). Menggunakan konsep dari Pedoman Smart City menurut SCI, maka penjajakan yang di dalamnya terdapat komunikasi dan kunjungan personil Pemerintah Kota Bandung - meskipun dalam beberapa kali kesempatan Walikota Bandung Ridwan Kamil hadir secara langsung, menjadi momen dari fase Proses Perencanaan (Sistercity, 2020).

Dalam proses ini juga, pemerintah Kota Bandung menunjuk konsultan LAPI ITB pada tahun 2013 untuk kemudian merancang Rencana Induk Pengembangan Smart City Kota Bandung. Penunjukan ini merupakan penunjukan langsung mengingat ITB melalui LAPI ITB telah memiliki sejumlah tenaga ahli. Salah satu contoh tenaga yang ahli di bidangnya adalah Prof. Dr. Ir. Suhono Harso Supangkat yang telah memiliki publikasi sebanyak 95 publikasi yang sebagian besar berbasis implementasi inovasi dan teknologi smart city (ITB, 2020).

Melalui KSP, pemerintah Kota Bandung mendapatkan fresh outlook (sudut pandang baru) terkait isu kebijakan melalui mutual learning (Information on Knowledge Sharing, 2020) Praktisi ahli Korea Selatan melakukan profiling. Profiling adalah metode riset kebijakan yang bermanfaat untuk memetakan tantangan dan peluang suatu persoalan yang bermanfaat untuk merumuskan solusi (Osborne \& Brown, 2012, p. 25). KSP mengundang dan mengijinkan pemerintah Kota Bandung untuk mendapatkan pengetahuan mengenai praktik baik secara efisien dan efektif yang diperoleh dari pengalaman Korea Selatan menjadi negara maju.

KSP juga memfasilitasi Pemerintah Kota Bandung sebagai mitra untuk memetakan tantangan yang dimiliki. Tantangan ini dirumuskan oleh tenaga ahli yang bekerja bersama berbagi pengalaman dan praktik untuk memformulasikan dan mengembangkan inisiatif kebijakan baru. Kebijakan yang diformulasikan pun disesuaikan dan diadaptasikan agar menghasilkan luaran dan timbal balik yang dapat praktis dan dapat diterapkan(Information on Knowledge Sharing, 2020). Dalam proses ini, Pemerintah Kota Bandung mengundang para tenaga ahli KSP untuk melakukan observasi langsung guna dapat merumuskan profiling yang secara akurat dapat memetakan peluang, tantangan, masalah yang ada sehingga dapat menghasilkan rumusan kebijakan yang lebih emulative dan adaptif. 
Khazanah Sosial, Vol. 2 No. 3: 141-154

Advokasi Kebijakan dalam Kerjasama Smart City Bandung dan Seoul lewat Kemitraan Sister City tahun 2016-2019

Fahrisya Tiko Septiarika, Enny Suryanjari

KSP juga memfasilitasi adanya pengembangan kapasitas (capacity building). Pengembangan kapasitas merupakan tujuan kunci dalam transformasi kebijakan ke suatu aksi nyata (Information on Knowledge Sharing, 2020). KSP menawarkan sejumlah mekanisme transformasi kebijakan ke suatu aksi kebijakan. Ini dapat dikenali pada masa advokasi kebijakan "Establishment of Bus System Reform Strategy in Bandung 2017/2018". Pemerintah Kota Bandung menghadiri sesi akhir dari laporan akhir advokasi kebijakan pada tanggal 6-9 Mei 2019 di Bandung.

Undangan yang hadir terdiri dari seluruh perwakilan Satuan Kerja Pemerintah Kota Bandung (SKPD) terkait mulai dari Dinas Komunikasi dan Informatika Kota Bandung, Dinas Pekerjaan Umum dan Perumahan Rakyat, Dinas Transportasi Kota Bandung, dan Badan Perencanaan dan Pembangunan Daerah Litbang Bandung. Sejak adanya Rencana Induk Pengembangan Smart City, telah ada komunikasi dan koordinasi lintas SKPD di lingkungan pemerintah Kota Bandung. Koordinasi dan komunikasi secara intensif dilakukan antara Dinas Komunikasi dan Informatika Kota Bandung, Dinas Pekerjaan Umum dan Perumahan Rakyat, bagian Pembangunan Pemerintahan Kota Bandung, serta Badan Perencanaan Pembangunan Daerah dan Litbang Kota Bandung. Dinas-dinas yang melakukan komunikasi domestik dan koordinasi agar Kota Bandung dapat mewujudkan smart city. Kesemuanya merupakan upaya yang dilakukan pemerintah Kota Bandung di awal perumusan kerjasama bagian penjajakan menurut (Saputra \& Supangkat (2019).

Selain itu pemetaan peluang dan tantangan juga tertuang dalam Rencana Induk Pengembangan Smart City yang dihasilkan oleh LAPI ITB. Rencana Induk mengurai tantangan yang dirangkum dalam tabel 1:

Tabel 1 Advokasi Kebijakan Pengembangan Smart City oleh LAPI ITB lewat Rencana Induk 2018

\begin{tabular}{|c|c|}
\hline Kondisi Kota Bandung Saat ini & Bandung Smart City \\
\hline $\begin{array}{l}\text { 1. Transportasi penuh kemacetan dan } \\
\text { kurang memudahkan masyarakat } \\
\text { sebagai pengguna } \\
\text { 2. Pelayanan kesehatan yang belum } \\
\text { terintegrasi dan data base yang tidak } \\
\text { diperbarui } \\
\text { 3. Lingkungan yang kurang mendukung } \\
\text { inovasi masyarakat kota } \\
\text { 4. Pendidikan yang tidak terintegrasi }\end{array}$ & $\begin{array}{l}\text { 1. Kelancaran, ketertiban, dan kemudahan dalam sistem } \\
\text { transportasi perkotaan } \\
\text { 2. Kemudahan layanan kesehatan masyarakat Kota } \\
\text { Bandung yang terintegrasi dengan suatu sistem } \\
\text { layanan } \\
\text { 3. Terciptanya lingkungan yang ramah untuk mendukung } \\
\text { efektivitas dan efisiensi kota (menciptakan masyarakat } \\
\text { inovatif) } \\
\text { 4. Sistem pendidikan yang terintegrasi antar orang tua, } \\
\text { siswa dan tenaga pendidik (ekosistem pendidikan) }\end{array}$ \\
\hline
\end{tabular}

Sumber: (Tentang LAPI ITB, 2020)

Rencana induk tersebut memuat problem yang dialami oleh Kota Bandung, dan solusi yang ditawarkan. Transportasi penuh kemacetan, misalnya, telah menempatkan mobilitas penduduk dalam situasi yang tidak menguntungkan. Banyak tempat yang harus ditempuh lebih lama menggunakan kendaraan roda empat meskipun jaraknya hanya beberapa kilometer saja. Kemacetan ini bukan hal yang sulit ditemukan di Kota Bandung.

Pelayanan kesehatan juga dinilai belum terintegrasi. Data base kesehatan bahkan tidak diperbaharui secara sistemik dan periodik. Ini mengakibatkan sulit untuk mendapatkan data yang benarbenar mencerminkan kondisi dan profil kesehatan Kota Bandung. Untuk mengatasi hal ini maka, 
Khazanah Sosial, Vol. 2 No. 3: 141-154

Advokasi Kebijakan dalam Kerjasama Smart City Bandung dan Seoul lewat Kemitraan Sister City tahun 2016-2019

Fahrisya Tiko Septiarika, Enny Suryanjari

pemerintah Kota Bandung dihimbau untuk membangun sistem informasi kesehatan yang terpadu dan pelayanan satu sistem.

Lingkungan adalah hal yang juga menjadi pertimbangan. Menurut rencana induk ini, lingkungan dianggap kurang mendukung masyarakat kota untuk berinovasi. Masih sedikit, ketika rencana induk pengembangan smart city disusun, ruang publik yang nyaman dan mendukung inovasi masyarakat. Inovasi yang dimaksud misalnya memungkinkan anak mudah Bandung yang memiliki pandangan visioner tentang fashion dan edukasi memiliki ruang publik untuk mengekspresikan diri. Adapun saran yang tertuang ialah pemerintah Kota Bandung perlu menciptakan lingkungan yang ramah guna mendukung efektivitas dan efisiensi kota sehingga masyarakat dapat berkembang secara progresif dan inovatif.

\section{Policy Diffusion}

Policy diffusion mengandung arti dimana suatu pemerintahan subnational membuat keputusan untuk mengadopsi inovasi kebijakan yang dipengaruh oleh pilihan-pilihan yang dibuat oleh pemerintahan subnational di negara lain (Rodrigues \& Mattioli, 2017).

Untuk mengetahui proses kerjasama Smart City dalam kemitraan Sister City dalam proses ini tidak mudah dikenali. Hal ini disebabkan Kota Seoul memiliki karakteristik yang cukup berbeda dengan Kota Bandung. Kota Seoul adalah ibukota negara sekaligus pusat seluruh kegiatan bisnis, ekonomi, hiburan, pariwisata dan lainnya yang membuatnya memiliki preferensi tinggi untuk dapat menjadi kota yang nyaman sekaligus inovatif. Dengan tuntutan itu, Kota Seoul berkembang lebih progresif di bidang penerapan inovasi dan teknologi. Sehingga rumusan kebijakan yang diimplementasikan Kota Seoul cukup canggih atau dengan kata lain state of the art. Melihat situasi demikian, maka penelitian ini menyimpulkan proses difusi yang terjadi yang mana kategorinya jatuh pada copying, emulation, dan combination membutuhkan suatu penilaian cermat.

Berdasarkan informasi yang berhasil dihimpun dari sumber sekunder dan primer, Pemerintah Kota Bandung berpedoman dengan visi dan misi walikota terpilih memiliki peta jalan dan master plan menjadi kota yang visioner dan bermartabat - mengutip dari motto Kota Bandung sendiri (Mugia, 2020). Kebijakan yang diterapkan oleh Kota Bandung, belum dapat dinilai apakah sudah terpengaruh secara langsung oleh setiap kebijakan yang diimplementasikan oleh Kota Seoul. Yang menjadi motivasi utama Pemerintah Kota Bandung untuk bermitra dengan Seoul dalam implementasi Smart City tidak lepas dari capaian Kota Seoul sebagai kota inovatif dan berbasis teknologi. Tren ini sedang semakin menguat sebagai paradigma pembangunan kota di Indonesia. Kota Bandung, menjadi salah satu pionirnya dan sedang melakukan pembangunan secara berkelanjutan agar dapat mewujudkan kota yang lebih baik.

Motivasi lain yang mendorong Pemerintah Kota Bandung melakukan mengadopsi kebijakan Seoul terutama di bidang tata kelola kota, perencanaan kota, dan e-government adalah ingin mengkatalisasi konsep pembangunan yang lebih berkelanjutan. Kota Bandung juga memiliki visi dapat meningkatkan kualitas hidup warganya, memajukan literasi pengetahuan dan menanamkan praktik pembangunan berkelanjutan dengan tujuan-tujuan jangka panjang yang lebih visibel.

Terdapat sejumlah persoalan struktural yang ditemukan, persoalan tersebut terletak pada tingkat partisipasi masyarakat yang tidak sepenuhnya bergerak secara digital. Masyarakat juga tidak bergerak secara fleksibel sehingga pergerakan manusia masih cukup terbatas. Hal ini juga dikarenakan profil Kota Bandung yang tidak setara dengan profil suatu ibukota. Sebagai tambahan, Kota Bandung hanyalah ibukota provinsi dan tidak menjadi ibu kota suatu negara. Dengan demikian proses copying, tidak benar- 
Khazanah Sosial, Vol. 2 No. 3: 141-154

Advokasi Kebijakan dalam Kerjasama Smart City Bandung dan Seoul lewat Kemitraan Sister City tahun 2016-2019

Fahrisya Tiko Septiarika, Enny Suryanjari

benar terjadi dan belum memiliki bukti fisik yang mendukung. Namun demikian, bukan berarti policy diffusion tidak terjadi. Perkembangan Kota Seoul sebagai Sister City Kota Bandung tetap menginspirasi Kota Bandung. Inspirasi ini berasal dari keinginan Kota Bandung untuk memiliki Light Rapid Transportation meskipun Kota Seoul bukan satu-satunya yang memiliki LRT. Kota Seoul diundang dalam memberikan advokasi kebijakan dan masukan secara profesional pengembangan LRT Kota Bandung di masa depan. Akan tetapi, wujud kerjasama ini masih belum diperbaharui lagi meskipun walikota telah membuka ruang agar Korea Selatan dapat berpartisipasi dalam lelang pembangunan LRT di tahun-tahun ke depannya ("Korsel Siap Bantu Wujudkan Bandung Smart City," 2017). Berdasarkan paparan di atas, maka penulis menyimpulkan jenis policy diffusion yang terjadi dalam proses advokasi kebijakan dengan Seoul, adalah tipe diffusion, combination dan emulation lebih daripada copying.

Proses combination dan emulation ini dapat terjadi jika meneliti kasus per kasus inovasi. Pemerintah Indonesia, belakangan ini sejak masa pemerintahan Presiden Susilo Bambang Yudhoyono telah membangun jalan akan pengenalan inovasi dan electronic government. Sama halnya dengan pemerintahan di negara maju yang semua tata kelola saat ini telah terintegrasi secara utuh secara lintas kementerian, departemen dan pemerintah daerah secara seamlessly. Menyimpulkan tentang ini, jadi upaya pemerintah Kota Bandung sebagian besar adalah melakukan kombinasi kebijakan yang idenya berasal dari advokasi kebijakan yang diperoleh dari Seoul melalui institusi yang ditunjuk misalnya KOFICE dan KSP. Sebagai catatan, dalam perumusan transportasi terpadu rute bus KSP menjadi institusi advokasi kebijakan yang paling berperan aktif. Tidak hanya di tingkat subnational government, KSP juga memberikan rekomendasi-rekomendasi kebijakan kepada pemerintahan Indonesia tentang sejumlah kajian yang diperlukan (III, 2018).

Berdasarkan tipe luaran, juga terdapat kebijakan pemerintah Kota Bandung yang terinspirasi dan menerapkan perubahan inovasi yang diperoleh dari advokasi KSP, namun demikian banyak kebijakan ini memiliki luaran berbeda dari rumusan masukan di awal. Salah satunya adalah kebijakan ketika revitalisasi sungai di Kota Bandung di lakukan. Idenya ingin mewujudkan inovasi bagaimana pemerintah Kota Seoul merubah sungai yang melintas di tengah Kota Seoul menjadi pusat destinasi jalan-jalan yang menarik. Hal ini telah disampaikan pada bagian tulisan yang menyoroti wajah Sungai Chong Gye Cheon sebelum dan sesudah restorasi.

Dalam advokasi kebijakan, juga penting untuk tetap mempertahankan prinsip-prinsip kerjasama Smart City.

Similarities merupakan salah satu prinsip penting dari implementasi kerjasama Smart City. Tulisan ini menggunakan pedoman implementasi kerjasama Smart City. Prinsip-prinsip lainnya antara lain: (1) Similarities (adanya kesamaan bersama); (2) Exchanges (adanya potensi pertukaran atau transfer dalam segi budaya, edukasi, rekreasi, ataupun ekonomi; (3) Berorientasi pada masyarakat (adanya kepemimpinan yang aktif, serta keterlibatan dan dukungan oleh masyarakat, melalui organisasi atau bisnis-bisnis yang sudah ada untuk membangun dan memelihara hubungan yang sudah ada); (4) Hubungan timbal-balik (pertukaran yang sifatnya positif dan berjalan dari dua arah); (5) Manfaat strategis (manfaat jangka pendek dan jangka panjang yang di dapat dari hubungan melebihi biaya publik yang harus dikeluarkan untuk menjalin ataupun memelihara hubungan yang sudah ada; (6) Eksklusivitas dan kedekatan (tidak memiliki hubungan Sister City dengan kota lainnya di negara yang sama atau lokasi yang berdekatan dari lokasi calon Sister City; (7) Kestabilan politik (kondisi politik yang stabil di negara tempat Sister City berada, sesuai dengan hasil pengumuman dari pemerintah pusat) (Nuralam, 2018). Menggunakan kerangka tersebut, maka implementasi kerjasama Smart City harus mengandung prinsip 
Khazanah Sosial, Vol. 2 No. 3: 141-154

Advokasi Kebijakan dalam Kerjasama Smart City Bandung dan Seoul lewat Kemitraan Sister City tahun 2016-2019

Fahrisya Tiko Septiarika, Enny Suryanjari

di atas. Untuk menyederhanakan bagaimana prinsip tersebut ditemukan dalam skema kerjasama, disusub pada bagan 1:

Bagan 1 Tahapan Implementasi Kerjasama Sister City Kota Bandung-Kota Seoul

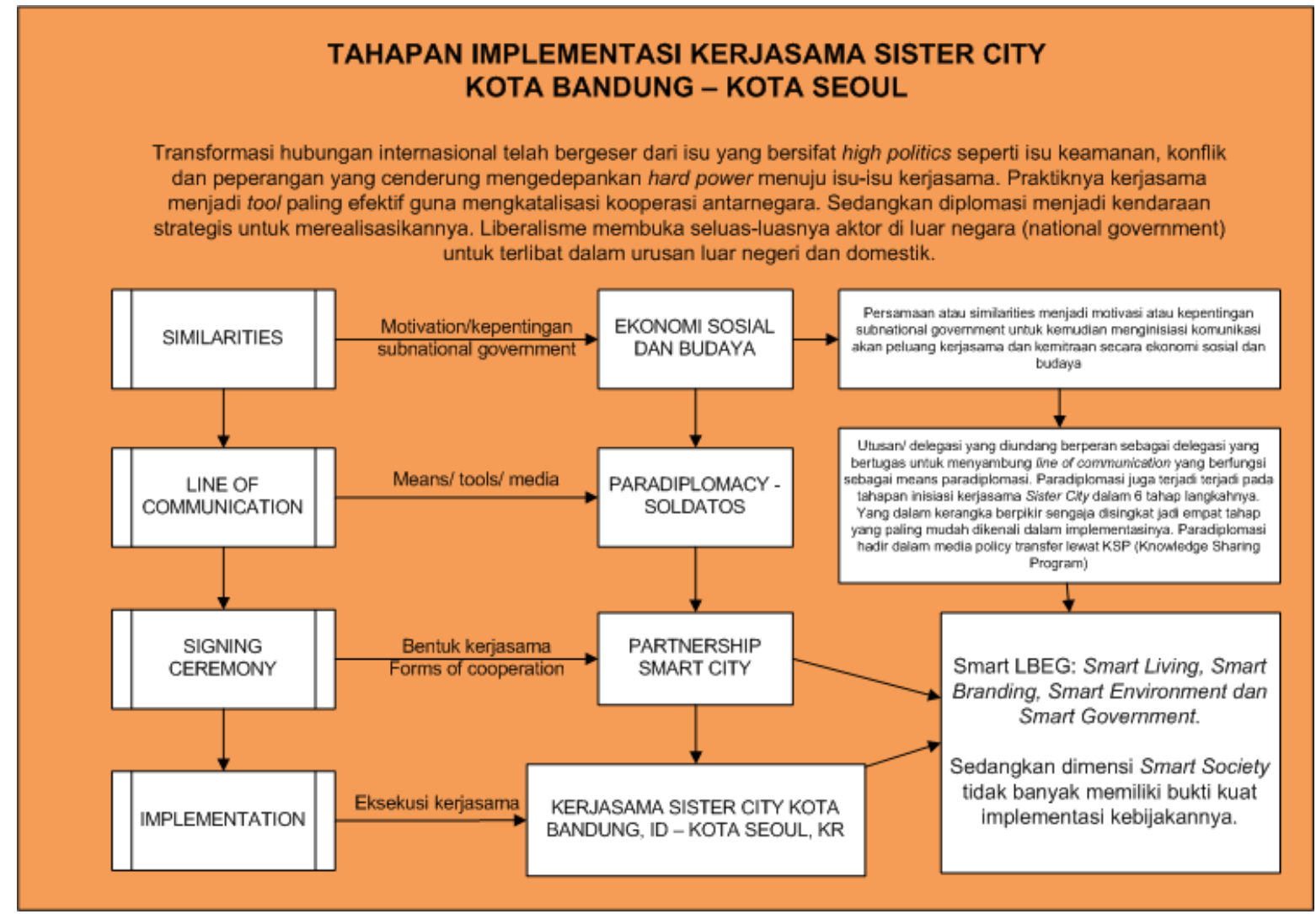

Sumber: diolah dari berbagai sumber oleh peneliti

Pemerintah Kota Bandung melakukan city profiling dengan meminta bantuan konsultan yang ditunjuk. Pekerjaan konsultan ini menghasilkan suatu rancangan induk pengembangan smart city. Selain itu pemerintah Kota Bandung juga berulang kali mengirim delegasi/ utusan untuk berkunjung ke kota seoul sekaligus melakukan observasi langsung terhadap peluang kerjasama dan kemitraan yang dapat dibangun oleh dua kota. Hal ini terwujud dalam pengiriman utusan untuk menghadiri ASEAN Connectivity Forum, berbagai summit dengan KOFICE dan KSP. Pemerintah Kota Bandung dan Seoul juga sepakat untuk membangun representasi kearifan kota di wilayah administrasi masing-masing.

Pemerintah Kota Bandung terlibat aktif untuk menjalin komunikasi dengan menghadiri berbagai festival yang mana Kota Seoul mengundang perwakilan pemerintah Kota Bandung (FA et al., 2020). Hal yang sama juga dilakukan oleh Kota Bandung hal ini sesuai dengan prinsip resiprositas yang menjadi salah satu prinsip dalam kemitraan Sister City. Pelajar Kota Bandung, misalnya, berpartisipasi dalam acara festival budaya yang dilaksanakan Kota Seoul untuk menunjukkan kesenian khas Kota Bandung, yakni Kesenian Sunda (FA et al., 2020). Selain itu juga terdapat pertukaran pelajar tingkat SMA - Mahasiswa untuk mengikuti program summer school berkolaborasi dengan sekolah dan universitas Kota Bandung (FA et al., 2020). Tidak hanya pertukaran pelajar, pertukaran staf di lingkungan Pemerintah Kota Bandung juga dilakukan. Aparatur Sipil Negara (ASN) di lingkungan Pemerintah Kota Bandung mendapat 
Khazanah Sosial, Vol. 2 No. 3: 141-154

Advokasi Kebijakan dalam Kerjasama Smart City Bandung dan Seoul lewat Kemitraan Sister City tahun 2016-2019

Fahrisya Tiko Septiarika, Enny Suryanjari

kesempatan untuk memelajari sistem pemerintahan dan mengikuti workshop Tax Department Seoul (FA et al., 2020). Upaya yang lain adalah dengan melakukan perjanjian kesepahaman atau MOU yang dilanjutkan dengan sejumlah perjanjian. Perjanjian ini antara lain perjanjian investasi membangun proyek LRT dengan nilai 37 juta USD. Kerjasama lain adalah dengan perusahaan swasta yang berasal dari Korea Selatan yaitu PT Total Solution Intelligent.

Hasil dari advokasi kebijakan tersebut melahirkan program sebagai hasil dari kerjasama Smart City. Program tersebut dapat dirangkum dalam tabel 2:

Tabel 2. Hasil Advokasi

\begin{tabular}{|c|c|}
\hline Dimensi Kerjasama & Implementasi Kerjasama \\
\hline Smart Government & $\begin{array}{l}\text { 1. Lokasi Wi-Fi Taman Dan Area Publik Di Seluruh Kota Bandung Mulai Dari } \\
\text { Taman Flexi Hingga Taman Film Di Jalan Layang Pasupati } \\
\text { 2. Mobil Pemberi Layanan Keliling Atau (MEPELING) Yang Diikuti Dengan } \\
\text { Rencana Ke Depan Berubah Berupa Pelayanan Publik Yang Lebih Terintegrasi } \\
\text { Atau Single Sign In. } \\
\text { 3. Kerjasama Yang Dilakukan Antara Tax Department Seoul Dengan BPPD Kota } \\
\text { Bandung } \\
\text { 4. Bandung Planning Gallery } \\
\text { 5. E-Planning Dan E-Budgeting }\end{array}$ \\
\hline Smart Branding & $\begin{array}{l}\text { 1. Bandung Techno Polis } \\
\text { 2. Business Lounge And Investment } \\
\text { 3. Little Seoul Atau Korea Street } \\
\text { 4. }\end{array}$ \\
\hline Smart Living & $\begin{array}{l}\text { 1. Kunjungan Dari Delegasi Korean Exim Bank Bersama Tim KSP Dessemination } \\
\text { Seminar. } \\
\text { 2. Kemitraan Dan Investasi Posco Steel Korea 21,5 Miliar } \\
\text { 3. Pemerintah Kota Bandung Mendapatkan Anggaran Tambahan Dari Perusahaan } \\
\text { Swasta Yang Berasal Dari Korea Selatan Yaitu PT Total Solution Intelligent } \\
\text { 4. Pertemuan ASEAN Connectivity Forum Bersama Korea Selatan, Tercantum } \\
\text { Bahwa Pihak Pengusaha Korea Selatan Tertarik Untuk Berinvestasi Dalam } \\
\text { Pembangungan Proyek LRT Dengan Jumlah Sebesar 37 Juta USD (ASEAN Korea } \\
\text { Centre, 2017) }\end{array}$ \\
\hline Smart Environment & $\begin{array}{l}\text { 1. Tata Kota Berkelanjutan Ramah Lingkungan Dan Ramah Community (Bisnis } \\
\text { Dan Masyarakat) } \\
\text { 2. Revitalisasi Sungai Cikapundung }\end{array}$ \\
\hline
\end{tabular}

Sumber : Diolah Peneliti 2020 
Khazanah Sosial, Vol. 2 No. 3: 141-154

Advokasi Kebijakan dalam Kerjasama Smart City Bandung dan Seoul lewat Kemitraan Sister City tahun 2016-2019

Fahrisya Tiko Septiarika, Enny Suryanjari

\section{SIMPULAN}

Kerja sama antara dua kota telah menghasilkan pembangunan ekonomi perkotaan, tata kota, transportasi kota, e-government. Kesemua pembangunan ekonomi tersebut dapat dikenali dalam kemitraan Sister City dalam dimensi Smart LBEG: Smart Living, Smart Branding, Smart Environment dan Smart Government. sTransfer kebijakan dan difusi kebijakan memainkan proses penting dalam mewujudkan implementasi kerjasama. Proses ini ditunjukkan melalui keterlibatan institusi yang ditunjuk oleh dua subnational government. Pemerintah Korea Selatan yang dikoordinasikan di bawah Kementerian Ekonomi dan Investasi Korea Selatan (MoEF Korea), program ini disebut Knowledge Sharing Program (KSP). Sedangkan pemerintah Indonesia melalui pemerintah Kota Bandung tidak didampingi oleh lembaga independen dengan fungsi serupa. Akhirnya Pemerintah Kota Bandung menunjuk LAPI ITB sebagai advocates kebijakan yang berfungsi memberi pengetahuan dasar diperlukan untuk merumuskan program dalam pengembangan Smart City. Baik LAPI ITB dan seluruh Satuan Kerja Pemerintah Daerah (SKPD) Kota Bandung terlibat dalam proses dan enam tahapan implementasi kerjasama Smart City.

\section{DAFTAR PUSTAKA}

Adibowo, R., \& Putri, S. O. (2016). Penerapan E-Government Dalam Paradiplomasi Pemerintah Kota Bandung. Jurnal Ilmu Politik Dan Komunikasi Volume VI No.

Aju, B. R. (2020). Alasan pemilihan kota seoul sebagai mitra kerjasama. In F. T. Septiarika (Ed.), Bagian kerjasama kota bandung (pp. 1-8).

Bramastya, R., \& Septiarika, F. T. (2020). KOTA BANDUNG SEBAGAI SUBNATIONAL GOVERNMENT DALAM KERJASAMA SMART CITY DENGAN KOTA SEOUL TAHUN 2016-2019. Publicio: Jurnal Ilmiah Politik, Kebijakan Dan Sosial, 2(2), 7-14.

Dolowitz, D. P., \& Marsh, D. (2000). Learning from abroad: The role of policy transfer in contemporary policy-making. Governance, 13(1), 5-23.

Duchacek, I. D. (1986). International competence of subnational governments: borderlands and beyond. Across Boundaries: Transborder Interaction in Comparative Perspective, 11-28.

Duchacek, I. D., \& Duchacek, H. (2019). The territorial dimension of politics: within, among, and across nations. Routledge.

FA, J. Q. A., Bainus, A., \& Riswanda, R. (2020). EVALUASI KERJA SAMA DAERAH KOTA BANDUNG (Studi Kasus Sister Cities antara Kota Bandung dan Kota Seoul). Moderat: Jurnal Ilmiah Ilmu Pemerintahan, 6(2), 350-360.

Hasibuan, A., \& Sulaiman, O. K. (2019). Smart City, Konsep Kota Cerdas Sebagai Alternatif Penyelesaian Masalah Perkotaan Kabupaten/Kota, Di Kota-Kota Besar Provinsi Sumatera Utara. Buletin Utama Teknik, 14(2), 127-135.

Hidayat, A. (2016). PENINGKATAN LAYANAN PUBLIK MELALUI SMART GOVERNANCE DAN SMART MOBILITY. Jurnal Administrasi Pembangunan, 4(2), 87-96.

III, K. P. C. (2018). 2017/18 KSP Policy Consultation: Support for the Establishment of Bus System Reform Strategy in Bandung, Indonesia. A Final report (M. o. E. a. F. K. (MFOK), Trans.). In K. P. Consultation (Ed.), Phase III (Vol. III).

Information on Knowledge Sharing. (2020). Information on Knowledge Sharing Program.

ITB. (2020). Profil Suhono Harso Supangkat. ITB.Ac.Id. https://www.itb.ac.id/staf/profil/suhonoharso-supangkat

Jönsson, C., \& Hall, M. (2005). Essence of diplomacy. Springer.

Kartini, I. A. (2014). Penerapan Prinsip Public Good governance Dalam Hubungan Internasional Melalui Perjanjian Sister City (Studi Kasus Sister City Kota Bandung). Kosmik Hukum, 14(2).

Kissinger, H. A. (1955). Force and diplomacy in the nuclear age. Foreign Aff., 34, 349. 
Khazanah Sosial, Vol. 2 No. 3: 141-154

Advokasi Kebijakan dalam Kerjasama Smart City Bandung dan Seoul lewat Kemitraan Sister City tahun 2016-2019

Fahrisya Tiko Septiarika, Enny Suryanjari

Liu, T., \& Song, Y. (2020). Chinese paradiplomacy: A theoretical review. SAGE Open, 10(1), 2158244019899048.

Marsh, D., \& Sharman, J. C. (2009). Policy diffusion and policy transfer. Policy Studies, 30(3), 269288.

Morgan, R. (1973). High Politics, Low Politics: toward a foreign policy for western Europe (Vol. 11). Sage Publications (CA).

Mugia, C. (2020). Implementasi Kerjasama bandung Seoul (NA, Trans.). In F. T. S (Ed.), Bidang Kerjasama Pemerintah Kota Bandung (Kerjasama Smart City dan Kemitraan Sister City ed., pp. 7).

Mursalim, S. W. (2017). Implementasi kebijakan smart city di Kota Bandung. Jurnal Ilmu Administrasi, 14(1), 126-138.

Neumann, I. B., \& Wæver, O. (1997). The future of international relations: masters in the making? (Vol. 4). Taylor \& Francis US.

Nuralam, I. P. (2018). Peran Strategis Penerapan Konsep Sister City Dalam Menciptakan Surabaya Green-City. Journal of Applied Business Administration, 2(1), 144-151.

Ogawa, A. (2012). Sister City as Preservation Strategy. Columbia University.

Pujayanti, A. (2018). Peran Daerah dalam Diplomasi Ekonomi. Jurnal Politica Dinamika Masalah Politik Dalam Negeri Dan Hubungan Internasional, 7(1).

Rahmadanita, A., Santoso, E. B., \& Wasistiono, S. (2018). Implementasi Kebijakan Smart Government Dalam Rangka Mewujudkan Smart City Di Kota Bandung. Jurnal Ilmu Pemerintahan Widya Praja, 44(2), 81-106.

Rodrigues, G. M. A., \& Mattioli, T. (2017). Paradiplomacy, security policies and city networks: the case of the Mercocities Citizen Security Thematic Unit. Contexto Internacional, 39(3), 569587.

Saputra, R. Wk. e-I. I. F. 2015, \& Supangkat, S. (2019). Quick Disaster Emergency Responses pada Pengembangan Kota Cerdas. Konferensi E-Indonesia Initiatives Forum 2015.

Sister City. (2019). 2019 Sister City International Directory Membership.

Sistercity. (2020). Guide to Establishing Sister City Relationships. Sistercity.Org. https://sistercities.org/wp-content/uploads/2017/10/Guide-to-establishing-a-sistercity-relationship.pdf

Soldatos, P. (1990). An explanatory framework for thestudy of federated states as foreign-policy actors. Federalism and International Relations: The Role of Subnational Units, 34-53.

Stone, D. (2012). Transfer and translation of policy. Policy Studies, 33(6), 483-499.

Tentang LAPI ITB. (2020). Tentang LAPI ITB. (2020). Tentang Kami. ITB. https://lapiitb.com/id/about 